University of Nebraska - Lincoln

DigitalCommons@University of Nebraska - Lincoln

2005 Bird Strike Committee-USA/Canada 7th

Annual Meeting, Vancouver, BC

Bird Strike Committee Proceedings

April 2005

\title{
North American Bird Strike Advisory System: Strategic Plan
}

\author{
Russell P. DeFusco, USAF (ret.) \\ BASH Incorporated \\ Michel J. Hovan \\ Federal Aviation Administration \\ James T. Harper , Lt. Col., USAF \\ USAF Institute for Information Technology Applications \\ Kurt A. Heppard \\ USAF Academy Department of Management
}

Follow this and additional works at: https://digitalcommons.unl.edu/birdstrike2005

Part of the Environmental Health and Protection Commons

DeFusco, Russell P. , USAF (ret.); Hovan, Michel J.; Harper, James T. , Lt. Col., USAF; and Heppard, Kurt A., "North American Bird Strike Advisory System: Strategic Plan" (2005). 2005 Bird Strike Committee-USA/ Canada 7th Annual Meeting, Vancouver, BC. 2.

https://digitalcommons.unl.edu/birdstrike2005/2

This Article is brought to you for free and open access by the Bird Strike Committee Proceedings at DigitalCommons@University of Nebraska - Lincoln. It has been accepted for inclusion in 2005 Bird Strike CommitteeUSA/Canada 7th Annual Meeting, Vancouver, BC by an authorized administrator of DigitalCommons@University of Nebraska - Lincoln. 


\section{North American Bird Strike Advisory System}

\section{Strategic Plan}
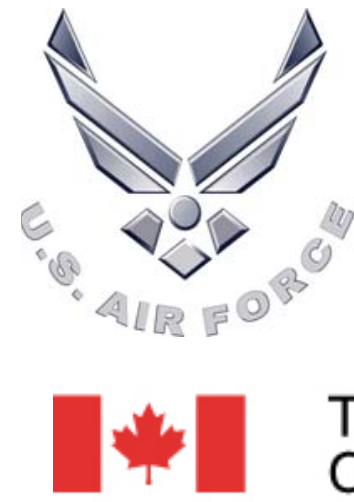

Transport

Canada

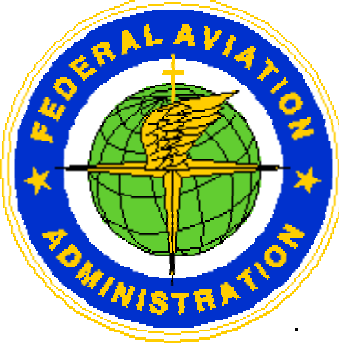

Transports Canada

Russell P. DeFusco, PhD, USAF (ret.)

BASH Incorporated

Michel J. Hovan, PhD

Federal Aviation Administration

James T. Harper, Lt Col, USAF

USAF Institute for Information Technology Applications

Kurt A. Heppard, PhD

USAF Academy Department of Management

April 2005

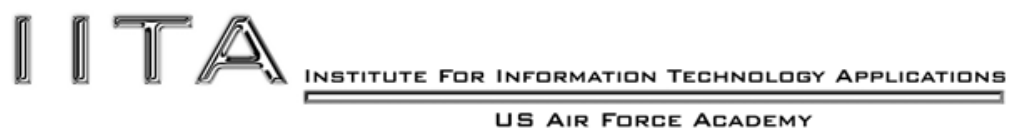




\section{Table of Contents}

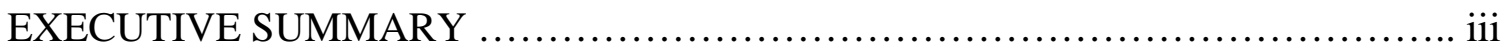

PART I - THE NORTH AMERICAN BIRD STRIKE ADVISORY SYSTEM-

BACKGROUND INFORMATION ............................................

Background ............................................................

Current Systems and Projected Development .................................4

Vision Statement ....................................................... 5

Mission Statement ..................................................... 5

PART II - THE NORTH AMERICAN BIRD STRIKE ADVISORY SYSTEM -

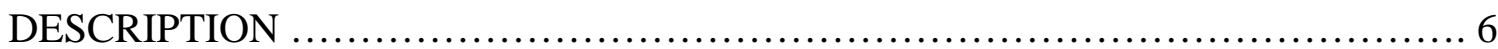

Concepts and Vision .................................................... 6

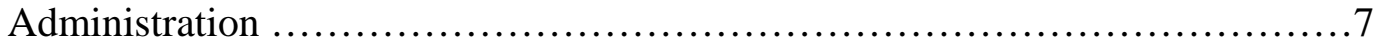

Data ................................................................... 9

North American Bird Strike Advisory System Implementation .................10

PART III - RESEARCH AND DEVELOPMENT GOALS AND OBJECTIVES .......12

North American Bird Strike Advisory System - Timeline .....................16

North American Bird Strike Advisory System - Budget ....................... 17

PART IV - NORTH AMERICAN BIRD STRIKE ADVISORY SYSTEM IMPLEMENTATION AND OPERATION .......................................18

PART V - NORTH AMERICAN BIRD STRIKE ADVISORY SYSTEM -

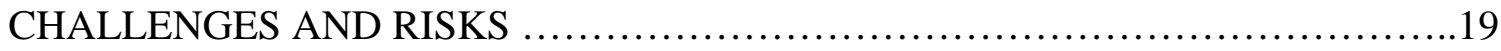

CONCLUSIONS AND RECOMMENDATIONS ............................... 21

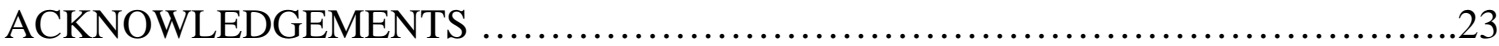

APPENDIX I - Background and Technical Information ..........................24

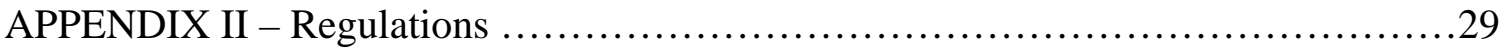

APPENDIX III - Supporting Documentation ...................................31 


\section{List of Figures}

Figure 1. 2002 Wild Turkey strike on commercial aircraft at Dulles International Airport ........................................................... 2

Figure 2. Canada Goose strike on radome of US Air Force C-141 ................. 2

Figure 3. September 1995 AWACS crash from Canada Geese struck at Elmendorf Air Force Base, Alaska ..................................................... 3

Figure 4. Conceptual depiction of a portion of the North American Bird Strike Advisory System ................................................... 6

Figure 5. Notional North American Bird Strike Advisory System ................... 7

\section{List of Tables}

Table 1. Ten-Year Research and Development Plan .................................................... 16

Table 2. Budget Estimates (In Thousands of Current Year US Dollars)....................... 17

Table 3. Technical Challenges and Risks ..................................................................... 19

Table 4. Non-technical Challenges and Risks ......................................................... 20

\section{IITA Overview}

The North American Bird Strike Advisory System Strategic Plan development effort was led by the Institute for Information Technology Applications (IITA). Located at the USAF Academy in Colorado Springs, Colorado, the IITA is an independent research center supported by the Air Force Office of Scientific Research. The institute conducts research for the Department of Defense, the Air Force, and the USAF Academy. IITA supports acquisition, educational and operational IT needs, develops an information-rich environment to prepare graduates for the high tech Air Force, and applies multidisciplinary expertise to IT research. IITA helps develop research topics, select researchers, administer sponsored research, publicizes results, and host conferences and workshops that facilitate the dissemination of information to a wide range of private and government organizations. With their multidisciplinary approach, the IITA was the logical sponsor of the North American Bird Strike Advisory Strategic Plan. 


\section{NORTH AMERICAN BIRD STRIKE ADVISORY SYSTEM STRATEGIC PLAN}

\section{EXECUTIVE SUMMARY}

The international aviation community recognizes the high human and economic costs associated with bird strikes. Hundreds of lives and millions of dollars have been lost in recent years because of this problem. Notably, aviation experts in North America recognize the importance and availability of potential solutions for this problem. Several models and systems such and the USAF's Bird Avoidance Model (BAM) and the Avian Hazard Advisory System (AHAS) as well as the technological development of advanced radar and communications systems have made great progress in addressing the problem of bird strikes. However, many have argued that further and much greater advancement could be made if the current fragmented and competitive efforts could be consolidated in a single cooperative venture.

This strategic plan is the initial step in a process of consolidating and integrating the various United States and Canadian civil and military efforts in order to develop and implement North American Bird Strike Advisory System. The plan has been developed based on the collected wisdom and technical knowledge of the top personnel and organizations in the field of aviation safety. If implemented, the plan will represent a critical first step leading to the realization of a North American Bird Strike Advisory System that will help protect aviators and their equipment from the deadly and costly effects of bird hazards.

The plan outlines the architecture of a notional bird strike advisory system for North America. It identifies the key agencies that must be involved in the development of the system. It establishes a top level schedule and identifies six key goals in developing an integrated system. The plan describes more detailed objectives and activities required to accomplish these goals. Recommendations are made regarding which agencies might most effectively take the lead in integrating various activities needed to accomplish each goal. It proposes a 5 year budget of approximately $\$ 16,000,000$ in order to support the initial phases of the effort. The strategic plan and its appendices also outline in considerable detail the key technical challenges, risks, and suggested organizational and technological solutions for these problems.

While reviewing this strategic plan, it's important to remember that it is not a detailed blueprint for developing and implementing the final system. Rather, it is a starting point for an evolving project and system that can be continuously developed and improved as technology and organizational systems become more advanced. The relatively modest budget proposed is essentially a "down payment" for the more robust system that will evolve based on this initial consolidation and integration effort. The plan represents an important first step in moving beyond fragmented competitive approaches to consolidated and integrated system that will save hundreds of lives and prevent a great deal of economic loss associated with destroyed or damaged aircraft and equipment. 
The plan highlights the many advantages of an integrated and consolidated bird strike advisory system. One such advantage is the improvement in the accuracy and fidelity of bird avoidance information to users in the aviation community. Another advantage of the proposed system is the synergistic use of data from new and existing radar and other systems to enhance reporting on bird activity without compromising the current effectiveness of those systems. Throughout the plan, the development of a robust communications infrastructure and network is described to enhance the timeliness and scope of bird advisory information delivery. 


\section{NORTH AMERICAN BIRD STRIKE ADVISORY SYSTEM STRATEGIC PLAN}

\section{PART I - THE NORTH AMERICAN BIRD STRIKE ADVISORY SYSTEM - BACKGROUND INFORMATION}

\section{Background}

Collisions between birds and aircraft have occurred since the earliest days of aviation. The bird strike problem has become more severe over time with crowded airspace, faster aircraft, and significant increases in hazardous bird populations. Globally, since 1990, there have been a minimum of 147 fatalities and over 120 aircraft lost due to bird strikes. It is virtually impossible to accurately calculate the costs of these incidents due to lack of mandatory reporting, differing reporting standards, indirect costs, and commercial interests; but by any measure the costs are staggering.

The United States Federal Aviation Administration (FAA) records an average of over 6,000 bird strikes per year to the civil aviation industry, including direct and associated costs at a minimum of $\$ 97.9$ million per year. Corrected for the estimated $80 \%$ of unreported strikes, costs may well exceed $\$ 489.8$ million per year. Figure 1 shows a 2002 bird strike on the nose of a civilian aircraft that occurred on departure from Dulles International Airport. Transport Canada (TC) estimates direct costs to its industry between \$64 and \$127 million US dollars annually from over 900 reported strikes per year and an estimated $30 \%$ unreported strikes.

The US Air Force (USAF) reporting rates are considered much higher than in the civilian sector due to mandatory reporting requirements. The USAF annually records approximately 4,000 bird strikes and direct costs of over $\$ 25$ million. The USAF recorded 22 lost aircraft and 33 fatalities since 1985. Figure 2 shows a bird strike on a USAF C-141.

Figures 1 and 2 show bird strikes that did not result in the loss of human lives. Figure 3 shows a September 1995 bird strike that resulted in an E3-B AWACS crash that claimed the lives of 22 Americans and 2 Canadians. 


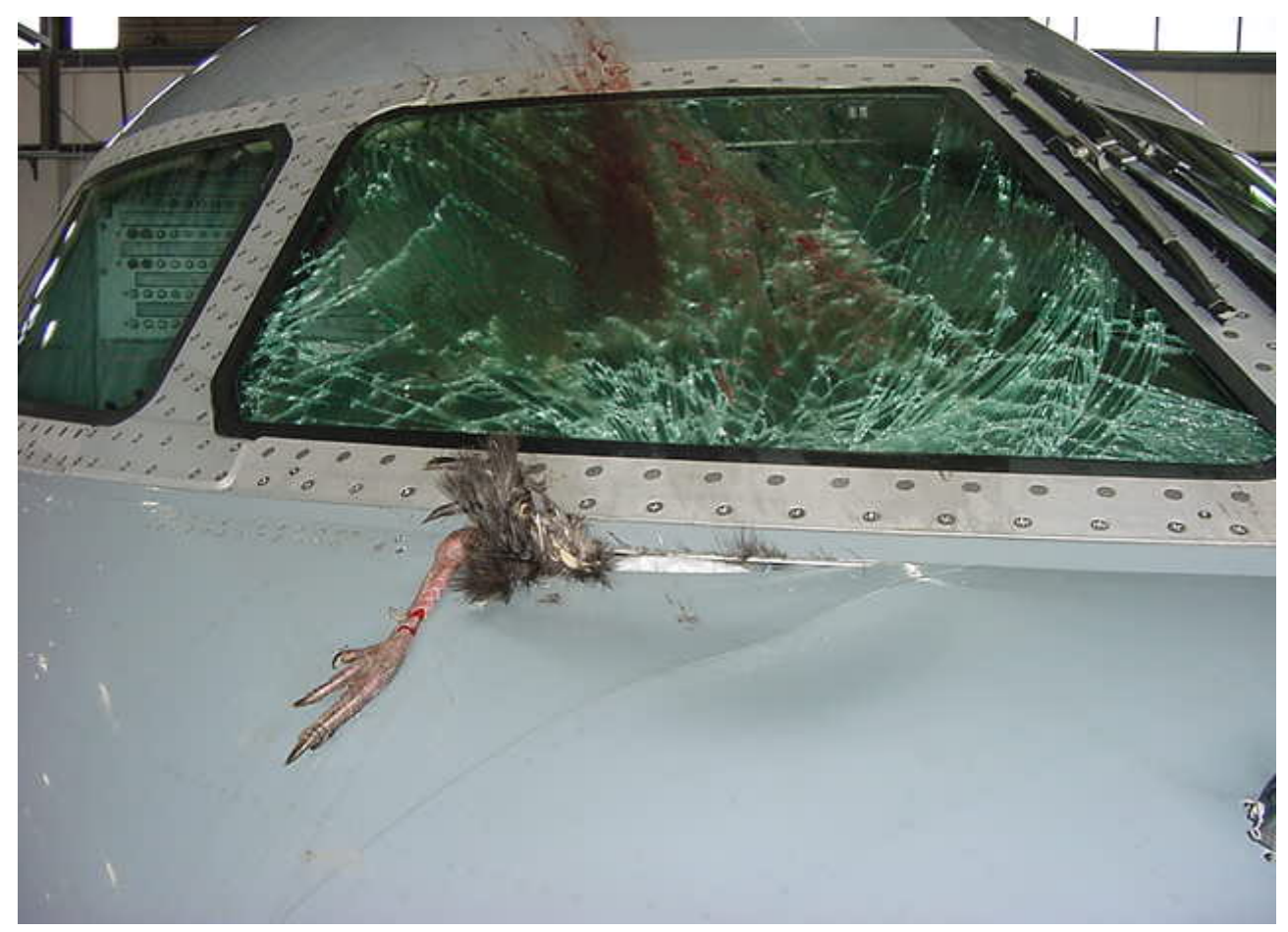

Figure 1. 2002 Turkey strike on commercial aircraft at Dulles International Airport.

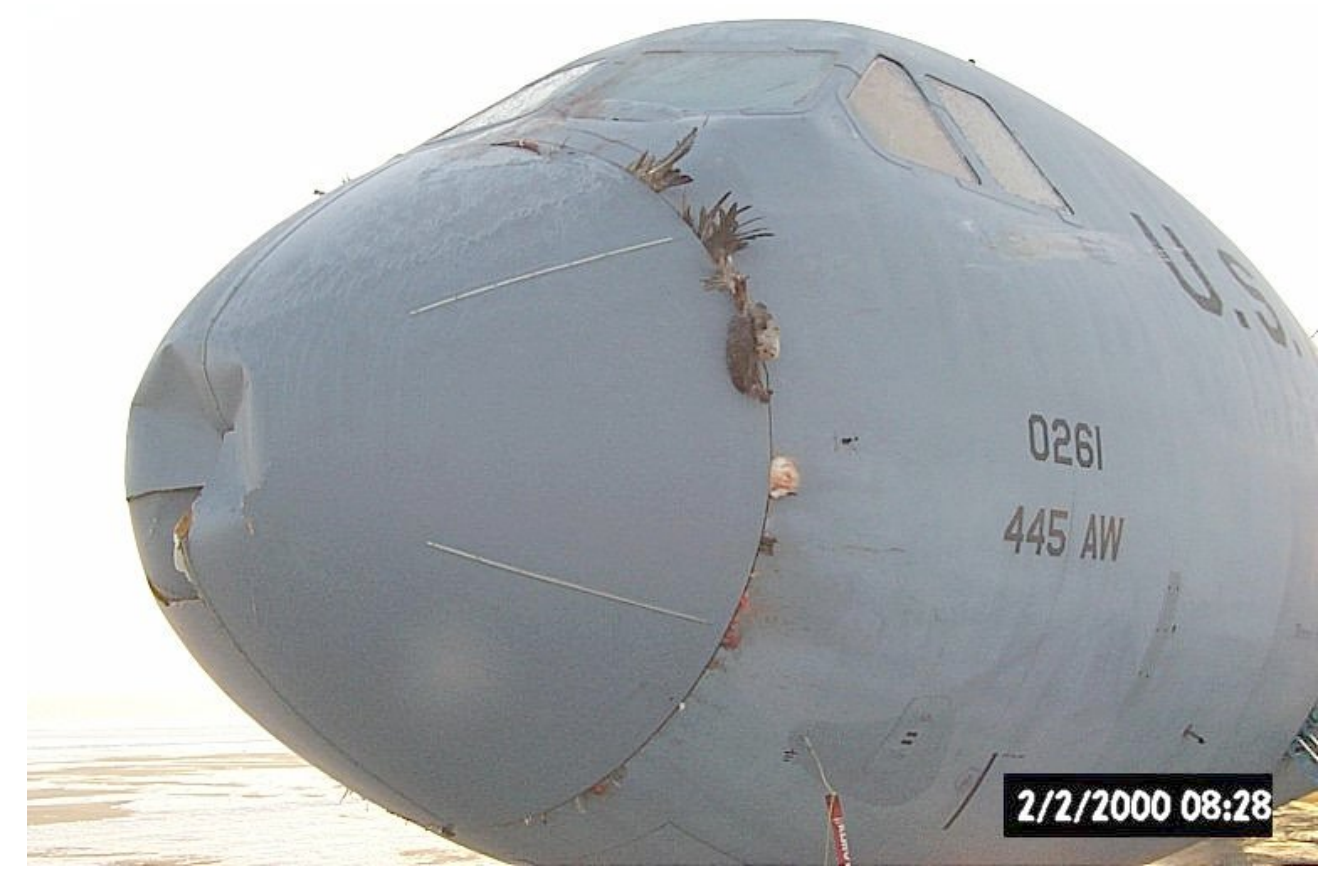

Figure 2. Canada Goose strike on radome of US Air Force C-141. 


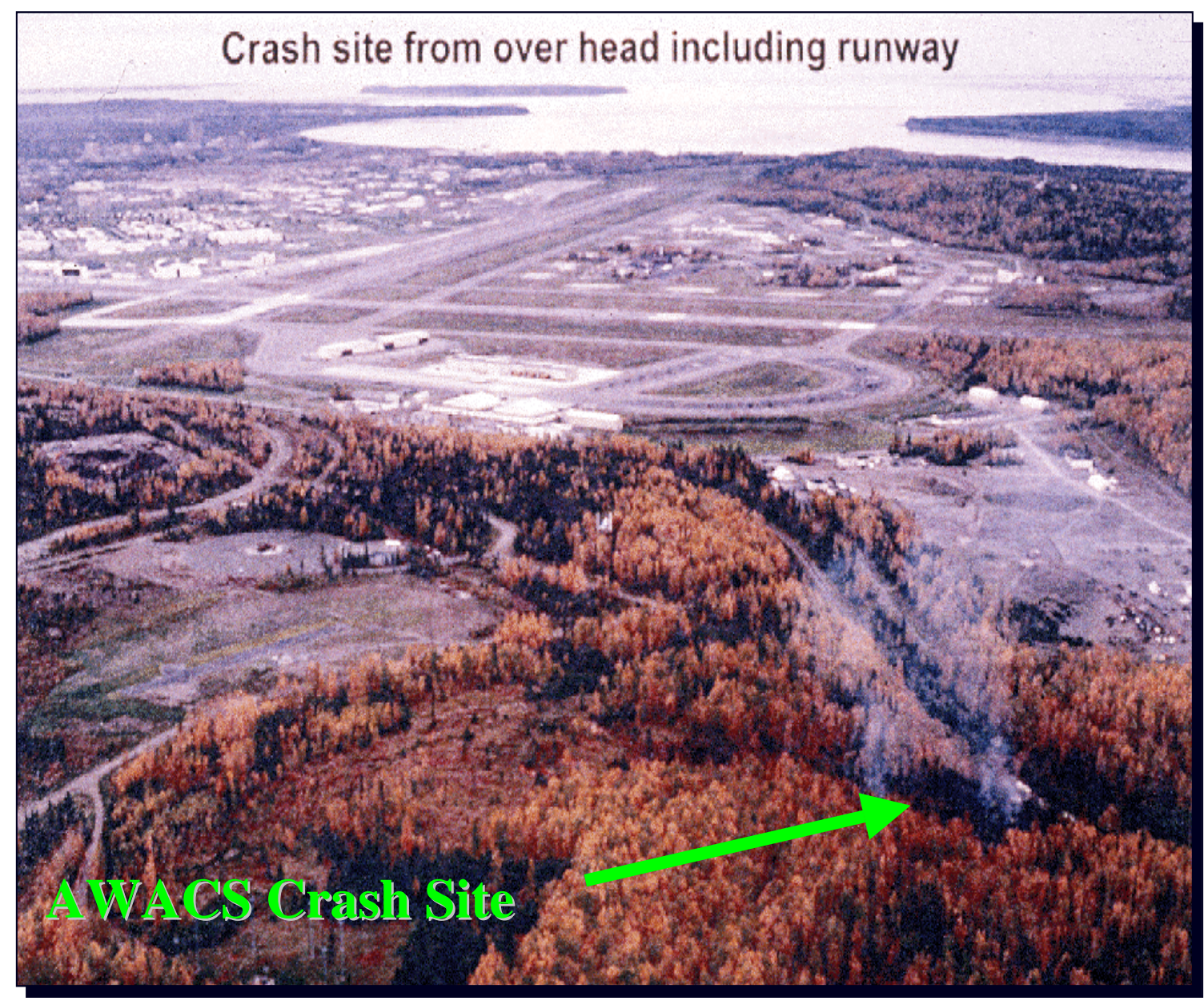

\section{Figure 3. September 1995 AWACS crash from Canada Geese struck at Elmendorf Air Force Base, Alaska.}

The US Navy and Marine Corps together report approximately 450 bird strikes annually costing an average of \$21.7 million per year in direct costs, including six lost aircraft and two fatalities since 1994. Indirect costs to the US Department of Defense (DOD) are not calculated, but exceed the above values by substantial margins. Aviation industry analysts calculate the total direct and indirect costs to the civil aviation industry at over $\$ 1.2$ billion US dollars annually. Insurance industry analysts place this figure much higher and conclude costs may approach \$4.5 billion US dollars annually for US and Canadian civil aviation alone.

While we may never know the exact costs attributed to bird strikes on civil and military aviation, the economic losses are extreme. The demonstrated potential for injury and loss of life is of greater concern.

The majority of reported bird strikes to both civil and military aircraft occur in the immediate airfield environment where control measures may be implemented to reduce hazardous bird conditions. Land use planning, habitat management, active and passive bird dispersal techniques, and population control measures are all effective means of lessening the risk. Such techniques are well defined and implemented at civil and 
military airfields around the world. However, analysis of civil and military strike records clearly indicates that once aircraft depart airport property, a disproportionate amount of damage and costs are incurred. Birds are difficult or impossible to effectively manage or control outside the boundaries of airports. Planning to avoid birds in time and space, and warning systems to enable evasion of birds in flight become the only viable options to manage off-airfield risks.

\section{Current Systems and Projected Development}

Historically based models such as the USAF's Bird Avoidance Model (BAM) aid in long-range planning for avoiding known concentrations of potentially hazardous birds throughout the continental United States and Alaska. The BAM provides data on over 70 species of birds considered most hazardous to low flying aircraft. These species are grouped and a composite biomass is applied for each square kilometer of the continental United States and Alaska. The cumulative weight of the hazardous species forms the basis for a bird risk surface mapped on a web-based application. The application allows users to select safest routes based on location, time of year, and time of day.

The Avian Hazard Advisory System (AHAS) provides a dynamic version of the BAM by updating the risk assessments every 10 minutes based on detection of birds and monitoring weather conditions conducive to bird movements. AHAS gathers data from the nationwide NEXRAD and other weather radar systems.

Small-scale mobile radars are available to monitor local bird movements in real-time at select locations. For several years, work has been conducted to develop and field a threedimensional airport bird detection radar (3-D ABDR) to detect, track, and monitor birds at commercial airports in Canada.

In addition to the above systems, existing radar infrastructure can be further exploited through the use of bird detection algorithms applied to such systems as terminal doppler weather radars, a variety of airport surveillance radars, national defense radars, and other systems.

European nations use weather and national defense radar networks to detect birds and provide warnings to pilots and decision makers. Other components are also currently being developed or proposed to address the issues of bird detection, forecasting, modeling, warning, and communications. Communications of bird strike advisories can potentially use technologies such as the Traffic Collision Avoidance System, the Automatic Dependent Surveillance - Broadcast, Aircraft Communication Addressing and Reporting System, Link-16, the Electronic Flight Bag, or others.

These diverse and various systems can be effectively used for planning, scheduling, and avoiding birds in time and space, and may also be used to trigger other actions such as active bird dispersal efforts. However, research and development efforts have not been effectively coordinated to create a fully integrated system for bird strike advisories throughout North America.

Appendix I provides more details on existing and proposed systems; Appendix II lists applicable civil and military regulations; Appendix III lists additional reference material. 


\section{Problem Statement}

At the current time, there are a number of problems that have encumbered the development of an integrated bird strike risk warning system throughout North America. These can be categorized as follows:

Organizational Structures. There is no centralized agency to conduct research and development of technology, to network communication systems, nor to implement procedures for North American civil and military bird avoidance programs.

There has been progress made in technological and research aspects of current bird avoidance research and development. However, implementation efforts are often uncoordinated, fragmented, and redundant, resulting in inefficient use of limited resources. The result is a patchwork of numerous bird strike risk reduction schemes of various quality and effectiveness.

Technical Challenges. The ability to detect or predict the presence of birds in such a way that they can be avoided in time or space is not fully developed. The detection of birds can rely on radar or other remote sensing technologies. The development of real-time predictive bird presence models is in its infancy.

Communications. The ability to communicate warnings following detection of bird hazards so that aerodrome staff can focus directed bird dispersal efforts is not developed. Beyond airport property, the ability to communicate meaningful and useful real-time warnings is virtually non-existent.

Policy. Policy coordination for bird avoidance procedures is incomplete. Policy organizations, decision makers, and users are poorly informed or unaware of potential solutions. The range of procedures and bird avoidance techniques are incompletely defined.

Funding. Sustained program funding for long-term research, development, and integration of a bird strike advisory system does not exist. Current efforts are individually funded by potentially cooperating governments and agencies in an ad hoc manner.

\section{Vision Statement}

Produce a real-time and widely available North American Bird Strike Advisory System that protects aircrew, passengers, and aircraft.

\section{Mission Statement}

Cooperatively research, develop, and implement advisory systems that will provide technological and procedural solutions to minimize the risk of bird strikes to civil and military aircraft. 


\section{PART II - THE NORTH AMERICAN BIRD STRIKE ADVISORY SYSTEM - DESCRIPTION}

\section{Concepts and Vision}

The North American Bird Strike Advisory System will be similar in appearance to United States and Canadian national weather information systems. Real-time information and predictions will be available on user-friendly, web-based maps at North American, national, regional, and local levels. Throughout this system development process, consultations with international stakeholders will be maintained to ensure global compatibility and standardization. The system will be accessible on-line and users will be able to extract real-time information at airport and regional levels. Figure 4 shows large scale bird hazard forecasting based on historical data and regional radar inputs. The inset depicts the airport-level representation of the local area around the Dallas-Fort Worth Airport using airport maps and radars.
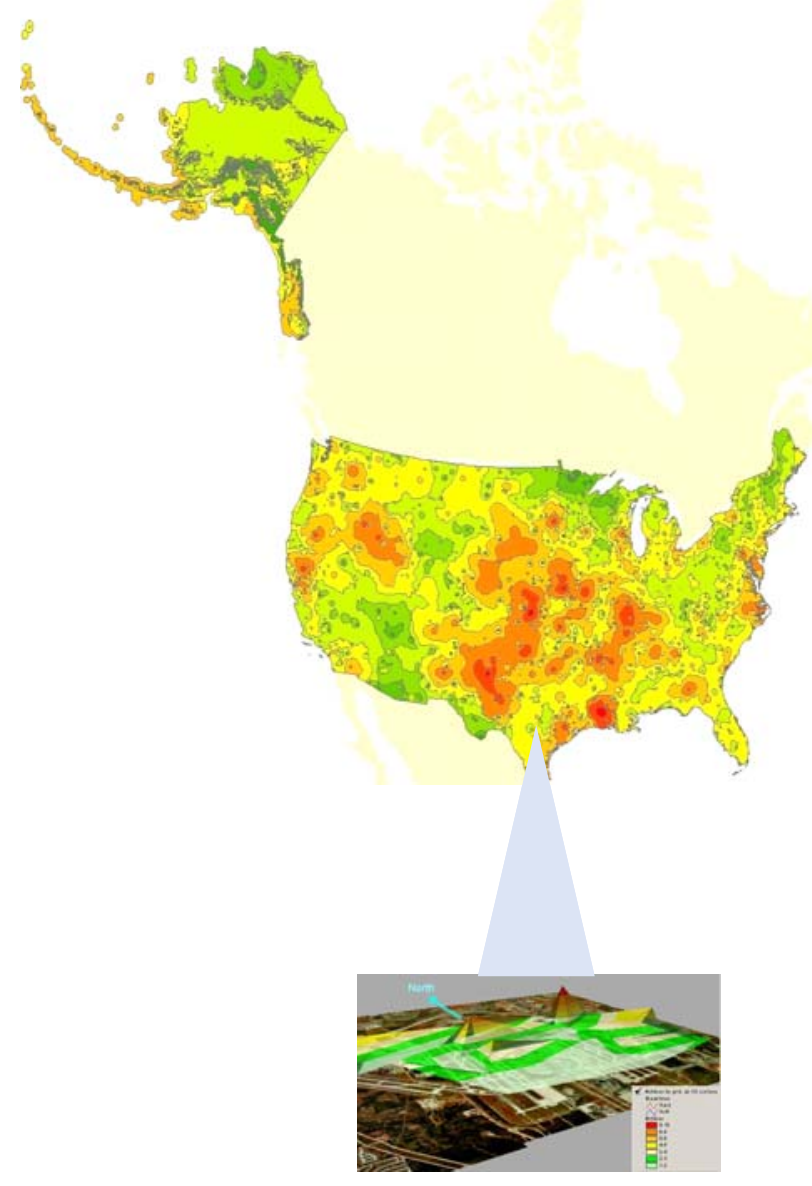

Figure 4. Conceptual depiction of a portion of the North American Bird Strike Advisory System 
There will be diverse users of the integrated system. At the airport level, airport personnel, air traffic controllers, and pilots will be able to access historical and real-time information. For flight planning purposes, pilots and airlines will be able to use information at the North American and national levels. In an approach mode, a pilot will also be able to get current updated information from either direct connect to the system, or via the airline operations center and military equivalents. Figure 5 is a notional representation of the North American Bird Strike Advisory System.

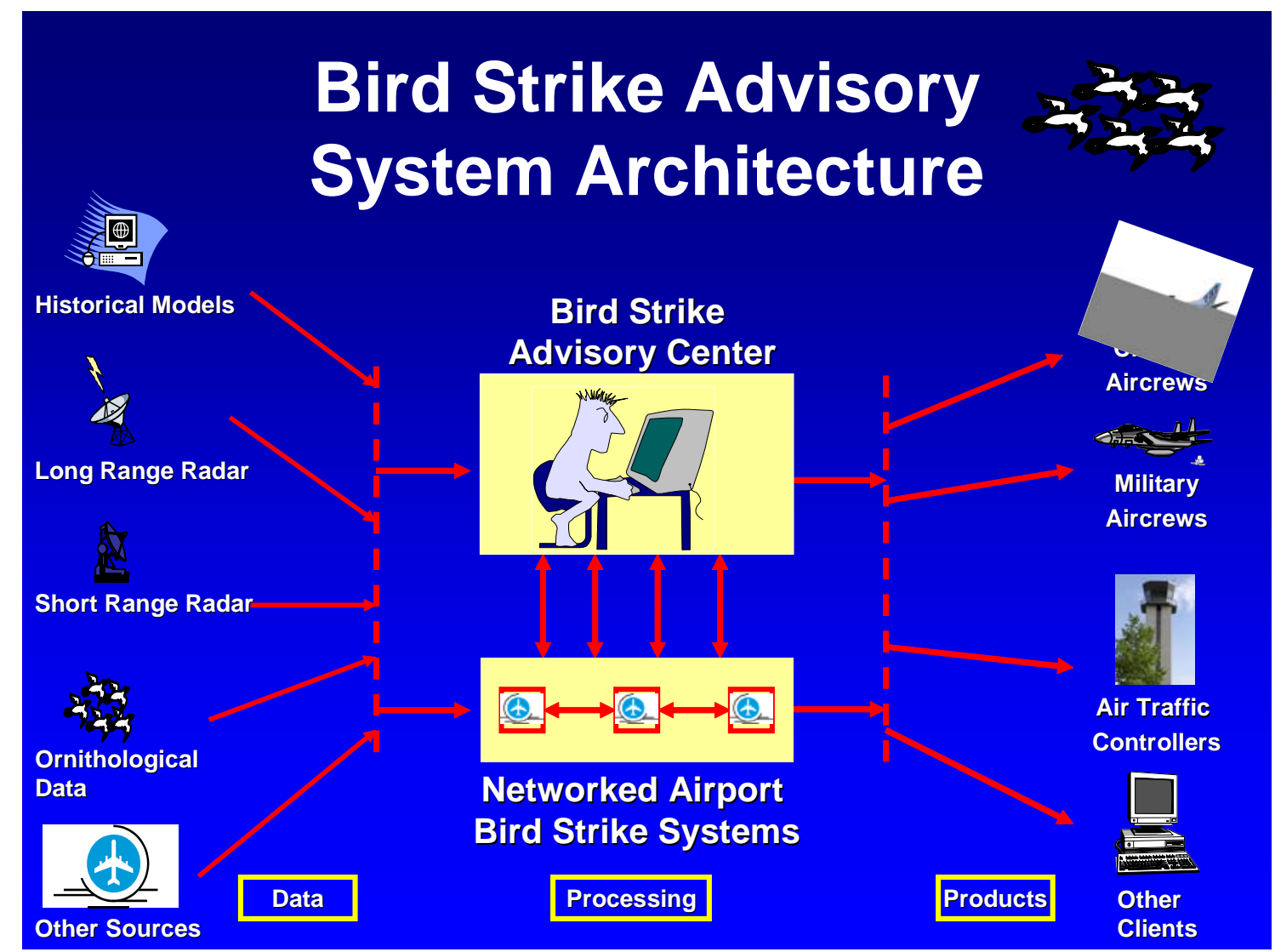

Figure 5. Notional North American Bird Strike Advisory System

\section{Administration}

Bird Strike Advisory Center. The Bird Strike Advisory Center (BSAC) is the central collection and distribution organization for the North American system. The BSAC's composition, location, and functions shall be defined by Memorandums of Agreement (MOAs) between the contributing governments and agencies. The BSAC functions as the operating arm of the Executive Board comprised of representatives from the contributing governments and agencies. The value of the BSAC lies in the following areas: 
- Ensures a centralized organization (can be virtual) that coordinates the integration of various components of the North American Bird Strike Advisory System.

- Collects, consolidates, and analyzes data and system inputs from the various bird detection technologies and communications.

- Provides data links to disparate operating system components throughout North America.

- Provides bird strike advisories to civil and military users throughout North America.

Executive Board. An Executive Board will oversee the integrated Bird Strike Advisory System for the United States and Canada. The Board will consist of Department Of Defense, Federal Aviation Administration, Transport Canada, and Canadian Department of National Defence representatives. The Board will convene ad hoc advisory committees when deemed necessary to address specific sub-components of the integrated system. The value of the Executive Board lies in the following areas:

- Helps ensure avoidance of duplication of efforts between contributing governments and agencies.

- Ensures sharing of technology and procedures between contributing governments and agencies.

- Creates a cooperative environment for research and development of components of the integrated system.

- Develops memorandums of agreement specifying roles and responsibilities of contributing governments and agencies.

- $\quad$ Secures funding for the Bird Strike Advisory Center and associated programs.

- Oversees research priorities and specific programs in support of the integrated system.

Program Manager. A Program Manager manages the program staff and administers the Bird Strike Advisory Center with oversight from the Executive Board. The value of the Program Manager lies in the following areas:

- Coordinates and implements the policies established by the Executive Board.

- Coordinates contracts for contributing agencies.

- $\quad$ Makes and oversees contractual agreements. 
- Serves as the intermediary between the users and the Executive Board.

- Oversees the processing of various data collected to produce a finished product for dissemination to the end users.

- Serves as the focal point for system queries from users.

- Provides policy and guidance for implementation of the bird strike advisory system in coordination with the end users.

Project Managers. The Project Managers manage individual research and development initiatives under guidance from the Program Manager. The value of the Project Managers lies in the following areas:

- Researches and develops bird detection systems for North American, national, regional, and localized applications.

- Coordinates data acquisition for hazardous bird concentration areas.

- Develops data management systems to depict and model hazardous bird concentration areas.

- Develops communication networks to provide bird advisory information in the long term, intermediate term, and real time.

- Identifies and develops capabilities to provide real time warnings to decision makers, airport operators, ground-based wildlife dispersal teams, and airborne users.

- Ensures standardization and integration of technological systems.

\section{Data}

Data will consist of historical and real-time information. Historical data includes the current United States Bird Avoidance Model (BAM) and is data that has been collected over many years in terms of bird species, population density, migratory patterns, relative bird strike risk, and operational airspace infrastructure. The Avian Hazard Advisory System (AHAS) provides dynamic updates to the BAM in near-real time at the regional level. Real-time data will be collected by radar at all levels. At the regional and national level, longer range radar may be able to detect bird migration patterns. At the airport or airfield level, dedicated radars must be able to detect birds in the critical airspace, defined as three-dimensional coverage out to five nautical miles and up to 3,000 feet above ground level. Data from other remote sensing technology may also be incorporated. These sub-components must be integrated into a networked and accessible system that is user-friendly and widely available. Research is necessary to determine the best methods to gather ornithological and operational data at various spatial and temporal scales. 
The goal is to provide effective bird strike warnings to pilots flying from one location to another. However, it is important to remember that:

- Bird presence by itself does not constitute a risk; not all birds represent danger.

- Bird presence must be correlated against aircraft type, flight scenario, and location in the airspace.

These points will be used as guidance rules during development of the system.

\section{North American Bird Strike Advisory System Implementation}

The implementation of the bird strike advisory system will be progressive, but offered at the local, regional, and North American level at the same time. In order for the North American Bird Strike Advisory System to be successful, research and development is required in the following areas:

- $\quad$ Establish the combined United States/Canada Bird Strike Advisory Center.

- $\quad$ Expand the United States BAM and AHAS into Canada.

- $\quad$ Establish a single web-based advisory system based on BAM and AHAS.

- Implement radar and other remote sensing technologies to provide near real time and real time bird hazard advisories at local and regional scales.

- Implement a bird strike risk warning system at the airport level. This can be done at a limited number of airports at the same time.

- Implement local-, regional-, national-, and North American-level bird strike advisory systems.

- Implement communications systems to provide bird strike advisories to ground-based and airborne users.

- Integrate the various airport bird strike risk warning systems into the consolidated North American Bird Strike Advisory System.

- $\quad$ Provide the system online.

\section{Potential components of an Airport-level Bird Strike Risk Warning System may include some or all of the following:}

- Basic mapping of bird densities: This will be done by developing tools to depict GIS and/or GeoBase maps of the airport and the surrounding area, and by adding bird density information versus time into the maps.

- Basic mapping of estimated bird strike risks: This will be accomplished by estimating and mapping bird strike risks at the airport and its surroundings. Estimates will be made by comparing bird density maps with aircraft 
departure and arrival paths, and further checked by previous recorded bird strikes at the airport.

- Reprocessing data from existing and/or future radars. This will be accomplished by capturing parallel streams of radar data, with supporting algorithms to detect birds using airport-level radars, without compromising air traffic control purposes for those radars.

- Augment basic mapping of bird strike risks with real-time detection. At one or more airports, small-scale radar will be deployed and radar information will be fed directly into the bird strike risk maps.

- Augment estimated bird strike risk maps and real time detection with realtime aircraft movement data.

\section{Potential components of an Off-Airfield Bird Strike Risk Warning System may include some or all of the following:}

- Basic mapping of bird densities: This will be done by developing tools to depict regional GIS and/or GeoBase maps at the national and North American level, as in the United States BAM, and by adding bird density information versus time into the maps.

- Basic mapping of estimated bird strike risks: This will be accomplished by estimating and mapping bird strike risks at the national and North American scale. Estimates will be made by compiling bird density maps and further checked by previous recorded bird strikes enroute.

- Reprocessing data from existing and/or future large scale systems such as weather radar and satellites. This will be accomplished by capturing parallel streams of data, with supporting algorithms to detect birds using regionallevel systems, without compromising the intended purposes for those systems.

- Augment basic mapping of bird strike risks with real time detection. Intermediate to large-scale radar will be deployed and radar information will be fed directly into the estimated bird strike risk maps.

- Augment estimated bird strike risks maps and real time detection with realtime aircraft movement data.

\section{Integrated Bird Strike Risk Warning System}

The off-airfield bird strike risk warnings will form the basis for embedding the localized and airport level systems into an integrated North American Bird Strike Advisory System. 


\section{PART III - RESEARCH AND DEVELOPMENT GOALS AND OBJECTIVES}

The North American Bird Strike Advisory System will be developed over a ten year period. It is difficult to forecast specific timelines beyond the five year point. Table 1 below contains the timeline for the various tasks required to field the complete system. Table 2 contains the budget estimates in current year United States dollars needed to research and develop the North American Bird Strike Advisory System. The table only lists budget estimates for the first five years.

The following six goals must be completed to field the complete North American system. However accomplishing these goals need not follow in sequential order:

\section{Goal 1: Expand United States BAM and AHAS into Canadian provinces and combine BAM and AHAS into one operational interface.}

Objectives: Continue the existing USAF BAM and AHAS research, development, and maintenance efforts. Expand BAM and AHAS into a consolidated North American system.

Activities:

1. Use state of the art techniques to upgrade United States BAM and develop Canadian BAM.

2. Combine United States and Canadian BAM into one web-based North American system.

3. Combine United States and Canadian AHAS into one web-based North American system.

4. Combine North American BAM and AHAS into one web-based system.

Recommended Research/Sponsor Agencies: USAF Institute for Information Technology

Applications

Canadian Department of National Defence

USAF Safety Center

Navy Safety Center

Canadian National Research Council

Transport Canada 


\section{Goal 2: Develop Geographic Information System (GIS) mapping tools for depicting birds at the individual airport level.}

Objectives: Use GIS maps to show bird hazards and resulting risks at and near airports. Provide airport-level risk management system at high resolution to complement the current 1 kilometer US BAM resolution.

Activities:

1. Develop bird risk management systems at the airport level.

2. Prototype and test at major airports.

Recommended Research/Sponsor Agencies: FAA Technical Center

USAF Institute for Information Technology

Applications

Transport Canada

Department of National Defence

Canadian National Research Council

United States Department of Agriculture

Goal 3: Integrate state of the art detection systems.

Objectives: Exploit current technologies, develop and test short, intermediate, and longrange radar-based as well as other remote sensing bird hazard detection capabilities. These capabilities must be explored over the full range of realtime and near real-time scales.

Activities:

1. Review state of the art radar and other remote sensing technology.

2. Develop algorithms to process radar and other remote sensing data to detect birds.

3. Determine the capabilities and limitations of detection systems.

4. Develop and evaluate user interfaces to depict automated radar returns.

5. Continue testing portable radars and other remote sensing technology.

6. Ground truth and calibrate detection systems.

Recommended Research/Support Agencies: USAF Research Lab

USAF Safety Center

Transport Canada

Canadian Department of National Defence

Canadian National Research Council

FAA Technical Center

US Navy Safety Center

National Weather Service

United States Department of Agriculture

United States Geological Survey 


\section{Goal 4: Develop and evaluate risk assessment system.}

Objectives: Use state of the art technology to determine how the presence of birds creates various levels of risk to aircraft and develop operational risk assessments.

Activities:

1. Develop risk assessment protocols; assess ecological and operational "Risk Factors.”

2. Develop risk assessment modules by combining detected and/or predicted bird hazards with aircraft movements.

3. Field test risk assessment module.

Recommended Research/Support Agencies: Transport Canada

FAA

Canadian Department of National Defence

USAF Safety Center

US Navy Safety Center

US Department of Agriculture

Canadian National Research Council

United Kingdom Central Science Lab

\section{Goal 5: Integrate airport/installation and regional real-time bird strike avoidance modules into North American system.}

Objectives: Create the combined US/Canada Bird Strike Advisory Center (BSAC) to manage integration of all system sub-components. The BSAC will collect, analyze, and consolidate historical, near real-time, and real-time bird hazard data at the local, regional, and North American scale.

Activities:

1. Establish the BSAC as a North American multi-agency governmental entity.

2. Integrate airport-level real-time bird strike advisory system through the North American scale.

3. Manage, standardize, collect, distribute, and archive data.

Recommended Research/Support Agencies: To be determined by the Executive Board 


\section{Goal 6: Implement the North American Bird Strike Advisory System and distribute bird strike advisories to users.}

Objectives: Develop airport- to North American-level bird strike risk management systems in compliance with GeoBase and/or commercial GIS systems. Develop communications networks to disseminate real-time, near real-time, and historical bird strike advisories from local to North American scale. The BSAC will distribute bird strike advisories.

Activities:

1. Display real-time system-detected hazards on GeoBase (US Air Force standard) or commercial GIS maps.

2. Analyze hazard maps using risk modules.

3. Produce and display airport-level risk maps and relay information to airport-level users.

4. Develop communications networks and processes to allow access to bird data at all levels.

5. Provide bird data to airports.

6. Provide bird data to air traffic control facilities.

7. Provide bird data to bird dispersal teams.

8. Provide bird data to Airline Operations Centers.

9. Provide bird data to aircrews.

10. Provide bird data to other users.

Recommended Research/Support Agencies: Bird Strike Advisory Center 


\section{North American Bird Strike Advisory System - Timeline}

\section{Table 1. Ten-Year Research and Development Plan}

Red lines indicate current efforts.

\begin{tabular}{|c|c|c|c|c|c|c|}
\hline & \multicolumn{6}{|c|}{ Bird Strike Advisory System } \\
\hline & $\mathrm{Y}-1$ & $\mathrm{Y}-2$ & Y-3 & $Y-4$ & Y-5 & Y6-10 \\
\hline $\begin{array}{l}\text { Goal 1. Expand United States BAM ar } \\
\text { AHAS into Canadian provinces and co } \\
\text { BAM and AHAS into one system }\end{array}$ & & & & & & \\
\hline Use state of the art techniques to upgra & & & & & & \\
\hline BAM and develop Canadian BAM & & & & & & \\
\hline Combine US and Canadian BAM & & & & & & \\
\hline Create/combine US and Canadian AHA & & & & & & \\
\hline Combine BAM and AHAS into one syst & & & & & & \\
\hline Goal 2. Develop GIS mapping tools & & & & & & \\
\hline $\begin{array}{l}\text { Develop bird risk management system } \\
\text { airport level }\end{array}$ & & & & & & \\
\hline Prototype and test at major airports & & & & & & \\
\hline $\begin{array}{l}\text { Goal 3. Integrate state of the art dete } \\
\text { systems }\end{array}$ & & & & & & \\
\hline $\begin{array}{l}\text { Review radar and other remote sensing } \\
\text { technology }\end{array}$ & & & & & & \\
\hline Develop algorithms & & & & & & -............. \\
\hline Determine capabilities of detection syst & & & & & & \\
\hline Develop user interfaces & & & & & & \\
\hline Continue testing portable radars & & & & & & \\
\hline Ground truth and calibrate detection sy & & & & & & \\
\hline Goal 4. Risk assessment & & & & & & \\
\hline Develop ecological/operational "Risk Fa & & & & & & \\
\hline Develop risk assessment modules & & & & & & -.............. \\
\hline Field test risk assessment module & & & & & & ............. \\
\hline $\begin{array}{l}\text { Goal } 5 \text {. Integrate airport/installation } r \\
\text { time bird strike modules into North An } \\
\text { system }\end{array}$ & & & & & & \\
\hline Establish advisory center & & & & & & -............. \\
\hline Integrate installation-level data & & & & & & -..........." \\
\hline Manage, standarize, collect, distribute, & & & & & & 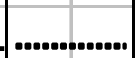 \\
\hline and archive data & & & & & & \\
\hline Goal 6. Distribute bird strike advisorie & & & & & & \\
\hline Display real-time radar detection hazaro & & & & & & \\
\hline Analyze hazard maps & & & & & & ............... \\
\hline Produce/display airport-level risk maps & & & & & & -............. \\
\hline Develop comm network and processes & & & & & & .............. \\
\hline Distribute data & & & & & & 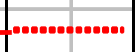 \\
\hline & & & & & & + \\
\hline Prototype/Field Integrated System & & & & & & 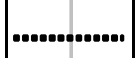 \\
\hline
\end{tabular}




\section{North American Bird Strike Advisory System - Budget}

\section{Table 2. Budget Estimates (In Thousands of Current Year US Dollars)}

\begin{tabular}{|c|c|c|c|c|c|c|}
\hline \multirow{2}{*}{$\begin{array}{l}\text { Goal 1. Expand United States BAM and } \\
\text { AHAS into Canadian provinces and combine } \\
\text { BAM and AHAS into one system }\end{array}$} & $\mathrm{Y}-1$ & $\mathrm{Y}-2$ & $\mathrm{Y}-3$ & $\mathrm{Y}-4$ & $\mathrm{Y}-5$ & Y6-10 \\
\hline & & & & & & \\
\hline $\begin{array}{l}\text { Use techniques used to develop Alaska BAM to } \\
\text { upgrade US BAM and develop Canadian BAM }\end{array}$ & 250 & 250 & & & & \\
\hline Combine US and Canadian BAM & \multirow[b]{2}{*}{150} & 75 & 75 & & & \\
\hline Create/combine US and Canadian AHAS & & 150 & 150 & & & \\
\hline Combine BAM and AHAS into one system & 75 & 150 & 150 & & & \\
\hline \multicolumn{7}{|l|}{ Goal 2. Develop GIS mapping tools } \\
\hline $\begin{array}{l}\text { Develop bird risk management systems at } \\
\text { airport level }\end{array}$ & 150 & & & & & \\
\hline Prototype and test at major airports & 300 & 200 & 200 & 200 & & \\
\hline \multicolumn{7}{|l|}{$\begin{array}{l}\text { Goal 3. Development of real-time and near } \\
\text { real-time detection systems }\end{array}$} \\
\hline $\begin{array}{l}\text { Review radar and other remote sensing } \\
\text { technology }\end{array}$ & 150 & \multirow[b]{2}{*}{250} & \multirow[b]{2}{*}{250} & \multirow[b]{2}{*}{250} & & \\
\hline Develop algorithms & \multirow[b]{2}{*}{75} & & & & 250 & -............. \\
\hline Determine capabilities of detection systems & & \multirow{2}{*}{75} & & & & \\
\hline Develop user interfaces & 50 & & 150 & \multirow[b]{2}{*}{250} & & \\
\hline Continue testing portable radars & 250 & 250 & 250 & & 250 & \\
\hline Ground truth and calibrate detection systems & 75 & 150 & 150 & 150 & 150 & \\
\hline Goal 4. Risk assessment & & & & & & \\
\hline Develop ecological/operational "Risk Factors" & 150 & 150 & & & & \\
\hline Develop risk assessment modules & & 150 & 150 & 150 & 150 & -............... \\
\hline Field test risk assessment modules & & & 150 & 150 & 150 & ............. \\
\hline $\begin{array}{l}\text { Goal 5. Integrate airport/installation real- } \\
\text { time bird strike modules into North American } \\
\text { system }\end{array}$ & & & & & & \\
\hline Establish advisory center & & 700 & 600 & 600 & 600 & |............. \\
\hline Integrate installation-level data & & & 250 & 250 & 250 & .............. \\
\hline $\begin{array}{l}\text { Manage, standardize, collect, distribute, } \\
\text { and archive data }\end{array}$ & & & 125 & 250 & 250 & \\
\hline Goal 6. Distribute bird strike advisories & & & & & & \\
\hline Display real-time radar detection hazards & & 250 & 250 & & & \\
\hline Analyze hazard maps & & 150 & 150 & 150 & 150 & .............. \\
\hline Produce/display airport-level risk maps & & 150 & 150 & 150 & 150 & .............. \\
\hline Develop comm network and processes & 100 & 200 & 300 & 300 & 200 & ............. \\
\hline Distribute data & 200 & 200 & 400 & 400 & 500 & ............. \\
\hline Yearly Totals (Thousands of US Dollars) & 1975 & 3650 & 3900 & 3250 & 3050 & |............. \\
\hline
\end{tabular}




\section{PART IV - NORTH AMERICAN BIRD STRIKE ADVISORY SYSTEM - IMPLEMENTATION AND OPERATION}

Doing It Now: There is technically no reason why we could not immediately start the research for implementing the steps laid out in this strategic plan. The approach is a stepby-step process with the overall system being integrated in the future. In Year One, funding agencies can sponsor the research and development of portions of the North American Bird Strike Advisory System. Over the years, additional research and development can be integrated into the complete system.

Overall Management: Research and development of the system will be managed from a central location. Representatives from various agencies will form a research and development team and will operate from that location. Stakeholders from each agency will form an Executive Board to provide input to the research and development teams. Management of airport systems will take place at the airport level with products and inputs provided to the integrated system in compliance with established standards.

At this time, it is too early to identify the agency or agencies responsible for managing the North American and national systems. The Executive Board will convene and make recommendations to identify participating organizations and agencies, and their contributions to the system. Specific Memorandums of Agreement (MOAs) must be developed to outline the roles and responsibilities of all participating agencies. For effectiveness and accountability under those agreements, a central location/agency will be designated as the Bird Strike Advisory Center (BSAC). The BSAC will be a joint United States/Canadian government initiative. Both the United States and Canadian governments will need to provide personnel for the BSAC organizational start-up phase, the research and development phase, and the operational phase. Likewise, both governments will need to appropriate sufficient money each year to ensure successful day-to-day operations. The BSAC will provide North American bird strike advisories at the North American level and will link to all airport-level systems. For example, agencies such as the Air Force Research Laboratory, the Air Force Office of Scientific Research, Defense Advanced Projects Agency, FAA Technical Center, Transport Canada Transportation Development Centre, Canadian National Research Council, or others could sponsor and fund radar research on existing and future systems under the direction of the Executive Board and the BSAC. Communication networks could be researched and developed using FAA Air Traffic Services, Transport Canada Air Traffic Services, DOD Global Information Grid, and other agency support.

Data Acquisition by the Users: Data will be acquired by the users online. Two modes of data delivery will be tested.

Passive Mode - Users can query the system to get real-time and historical information as part of flight planning, airport management, or other uses.

Warning Mode - Automated warnings will be issued when the system has identified potentially hazardous concentrations of birds. One example is heavy migration of large birds in critical airspace. A warning, similar in nature to a Notice to Airmen (NOTAM), and called a BIRDTAM, will be issued by the system to all identifiable users. 


\section{PART V - NORTH AMERICAN BIRD STRIKE ADVISORY SYSTEM - CHALLENGES AND RISKS}

Table 3. Technical Challenges and Risks

\begin{tabular}{|c|c|c|}
\hline Technical Challenge & Risk & Description \\
\hline $\begin{array}{l}\text { Creating Canadian versions } \\
\text { of the United States BAM } \\
\text { and AHAS systems }\end{array}$ & Medium & $\begin{array}{l}\text { Using the techniques developed for the } \\
\text { Alaska BAM, research and build a BAM for } \\
\text { the Canadian Provinces. Research and build } \\
\text { a Canadian equivalent to the US AHAS. }\end{array}$ \\
\hline $\begin{array}{l}\text { Merge North American data } \\
\text { into one web-based system. }\end{array}$ & Medium & $\begin{array}{l}\text { Research and develop a web-based } \\
\text { application that merges the BAM and AHAS } \\
\text { systems into one common system with web- } \\
\text { based graphic outputs. }\end{array}$ \\
\hline Detecting dangerous birds & High & $\begin{array}{l}\text { The key is to detect the dangerous birds, not } \\
\text { any bird, with high probability of detection } \\
\text { and low false alarm rates. }\end{array}$ \\
\hline $\begin{array}{l}\text { Radar data transmission in } \\
\text { real-time }\end{array}$ & High & $\begin{array}{l}\text { The issue is filtering, processing, and } \\
\text { transmitting radar data with little lag time. }\end{array}$ \\
\hline Hazards mapping & Low & $\begin{array}{l}\text { GIS maps already exist at a number of } \\
\text { airports. The key is to use the same format } \\
\text { and provide data to the centralized system. }\end{array}$ \\
\hline Risk mapping & High & $\begin{array}{l}\text { The mapping of actual risks is difficult and } \\
\text { involves estimating probabilities that a strike } \\
\text { can result in damages to aircraft and/or loss } \\
\text { of life. }\end{array}$ \\
\hline $\begin{array}{l}\text { Integration into one North } \\
\text { American system }\end{array}$ & High & $\begin{array}{l}\text { It will be critical to properly scope the } \\
\text { requirements for server and communications } \\
\text { support. Failure to properly scope needs } \\
\text { could result in a failure to acquire and } \\
\text { transmit real-time bird avoidance data to air } \\
\text { traffic control facilities and aircrews. }\end{array}$ \\
\hline $\begin{array}{l}\text { Incorporate bird strike } \\
\text { advisory data into GeoBase }\end{array}$ & Medium & $\begin{array}{l}\text { GeoBase is the standard GIS application for } \\
\text { United States Air Force installations and may } \\
\text { become the standard for DOD installations. } \\
\text { For those installations that use GeoBase, } \\
\text { create a GeoBase layer for real-time bird } \\
\text { strike advisory information. }\end{array}$ \\
\hline
\end{tabular}


Table 4. Non-technical Challenges and Risks

\begin{tabular}{|c|c|c|}
\hline Non-Technical Challenge & Risk & Description and Solution \\
\hline Funding & High & $\begin{array}{l}\text { Potential low budgets from funding agencies } \\
\text { are the reason to pool resources under one } \\
\text { effort. The key will be to cooperate. Even } \\
\text { with low budgets, the proposed step-by-step } \\
\text { approach makes this plan feasible. It is } \\
\text { critical to receive multi-year funding. } \\
\text { Without multi-year budgets, the North } \\
\text { American Bird Strike Advisory System will } \\
\text { be developed piecemeal and as a result will } \\
\text { not satisfy the goals of a complete, } \\
\text { compatible system. }\end{array}$ \\
\hline Organization & Medium & $\begin{array}{l}\text { The key is to agree and to continue to } \\
\text { cooperate. The challenge will be to create } \\
\text { and continually fund an international } \\
\text { organization to research and develop the } \\
\text { North American Bird Strike Advisory } \\
\text { System. The next challenge will be to create } \\
\text { an international organization (the BSAC) } \\
\text { with proper personnel and funding to operate } \\
\text { the North American Bird Strike Advisory } \\
\text { System. }\end{array}$ \\
\hline Policy & High & $\begin{array}{l}\text { Civilian and military regulatory agencies } \\
\text { must develop policies to implement a } \\
\text { standardized North American Bird Strike } \\
\text { Advisory System. }\end{array}$ \\
\hline Acceptance & Medium & $\begin{array}{l}\text { Demonstration will be conducted to gain } \\
\text { acceptance from users. }\end{array}$ \\
\hline
\end{tabular}




\section{CONCLUSIONS AND RECOMMENDATIONS}

Bird strikes to civil and military aircraft have posed severe safety and economic problems throughout the world and in North America. While it is accepted that many strikes may occur regardless of implementation of mitigating measures, it is also well established that proper operational planning and avoidance procedures based on early warning systems can significantly reduce potential risks. Many such systems are currently employed or are under research and development. Some of these operating systems have clearly demonstrated the potential to reduce risks to equipment as well as injury and loss of life. Existing systems will form the basis for the future cooperation proposed in this strategic plan. A variety of government and private agencies have worked to develop and analyze these systems. However, coordination among various entities engaged in these efforts has often been lacking, resulting in fragmented systems and competition for scarce resources. The purpose of this strategic planning document is to fully integrate all the disparate systems currently under deployment, development, or proposal. Cooperation between government and other agencies can help all involved in these processes to ensure an integrated, compatible, coordinated North American Bird Strike Advisory System for the benefit of all civil and military aviation operations. It is important that all governments and agencies agree to cooperate in this effort and envision how such cooperation will benefit all users of the integrated system. Details of such cooperation will be further developed in a series of Memorandums of Agreements (MOAs) in support of this plan.

RECOMMENDATIONS. To successfully field an integrated North American Bird Strike Advisory System, several initiatives and actions are recommended. These include:

- Establish Memorandums of Agreement among contributing governments and agencies to specify roles and responsibilities for each of those entities.

- Determine funding sources and sponsors required to develop the North American Bird Strike Advisory System.

- Establish long-range budgets within the participating governments and agencies to sustain continuous progress in the development, integration, implementation, and maintenance of the North American Bird Strike Advisory System.

- Consolidate resources, technology, and expertise from all participating organizations to leverage funding, ensure compatibility, and create synergism in the development of an integrated advisory system.

- $\quad$ Establish the combined United States/Canada Bird Strike Advisory Center.

- Establish an Executive Board comprised of representatives from the participating agencies to oversee and prioritize the research and development efforts required for the integrated system. 
- Designate a Program Manager through the Executive Board to operate the Bird Strike Advisory Center and coordinate efforts required to field an operational North American Bird Strike Advisory System.

- Appoint Project Managers to manage and conduct research and development of individual components of the integrated system.

- Establish a forecast advisory system based on historical data and models.

- Implement radar and other remote sensing technologies to provide near real time and real time bird hazard advisories at local and regional scales based on algorithms developed for existing and future technologies.

- Develop communications systems to provide bird strike advisories to groundbased and airborne users.

- Develop standardized policies and procedures for application of the integrated advisory system for all users in the United States and Canadian military and civil aviation communities. 


\section{ACKNOWLEDGEMENTS}

There have been numerous contributors to this document; perhaps too many to name them all. We must however acknowledge several agencies and individuals who have made significant contributions to this effort. The staff of the USAF Institute for Information Technology Applications, along with the Federal Aviation Administration and Transport Canada, sponsored the development of this work providing material support and administration for the effort. Bruce MacKinnon of Transport Canada provided funding for preparation of the document and associated travel expenses, as well as technical and editorial contributions to the document. Eugene LeBoeuf, Chief of the USAF Bird/Wildlife Strike Hazard Team at the USAF Safety Center provided invaluable inputs and the core of the systems that form the basis for the newly proposed North American Bird Strike Advisory System. Ed Cleary, FAA Staff Biologist provided sponsorship for research and development in support of civil bird strike avoidance programs and technical consultation on this document. Other technical and editorial contributions were provided by Robert Dogan of the Air National Guard Bureau, Matt Klope of US Navy BASH program, Ken Bassard from the FAA Air Traffic Services, Michael Begier of the US Department of Agriculture/Wildlife Services, Ronald Merritt and Adam Kelly of DeTect Incorporated, Edwin Herricks of the FAA Center of Excellence at the University of Illinois, Kristie Sweeney of AET Environmental, Paul Eschenfelder, Captain at Northwest Airlines and Airline Pilot's Association Safety representative, Kristal Alfonso and Jeffrey Merrell of the USAF Academy Department of Management, and Kristi Russell of Transport Canada. We would also like to acknowledge the contributions and coordination of our international partners in this effort; Wilhelm Ruhe of the German Bundeswehr Geoinformation Office, Luit Buurma, Chairman of the International Bird Strike Committee, and John Allan of the United Kingdom's Central Science Laboratory. The outstanding international, multi-agency cooperation was essential to the development of this Strategic Plan and ultimately to the success of the North American Bird Strike Advisory System. 


\section{APPENDIX I - Background Technical Information}

\section{Current Bird Avoidance Systems}

BAM: In the early 1980s, a Bird Avoidance Model (BAM) was conceived by the United States Air Force to warn flight crews of bird activity. By compiling historical data on hazardous bird populations and their movements, BAM gives pilots and mission planners the information needed to avoid known concentration areas. Through BAM, bird density is overlaid on a standard map. Each square kilometer of the 48 contiguous United States and Alaska is assigned a unique bird density risk value. BAM provides data on over 70 species of birds considered most hazardous to aircraft flying at low levels. To simplify the system, these species are grouped into composite groups according to behavior. BAM is accessed through a menu-driven, Web-based PC program, allowing users to obtain bird hazard information according to geographic locations, time of year, time of day, and selected routes. By comparing the relative risk of different flight plans, users are able to select the safest times and locations in which to fly. BAM has proven to be an extremely useful tool in forecasting bird positions based on past knowledge of their locations. Flight planners and pilots in all aviation sectors can use this information for planning flights.

AHAS: The Avian Hazard Advisory System was established in October 1998 to monitor bird activity over large geographic regions, and on military training routes, ranges, and airspace in near real time, and forecast bird activity up to 24 hours in advance. AHAS uses the BAM as its underpinning and provides a dynamic version of the BAM. The system uses data from the 144 NEXRAD Weather Radars distributed across the United States to detect biological targets in the atmosphere in near real time. The weather and bird, bat, and insect returns are identified using state of the art neural network technology. Bird activity is forecast by running models to predict migration of migratory birds such as waterfowl and the soaring dynamics of vultures, eagles, and hawks. The forecast system makes use of the extensive surface and upper air observations made by the National Weather Service and the weather forecast models they generate twice daily. AHAS is operational 24 hours a day, seven days a week. Staff members monitoring AHAS also work on the continuous improvement and development of the system.

Combining BAM and AHAS: Together, BAM and the AHAS are dependent systems that support long and short-term flight planning by focusing on bird movements and behaviors. In fact, AHAS was developed to extend the capacity of BAM and provide more immediate, near real-time information on bird concentrations and behaviors. Graphic output of AHAS data must be combined with the BAM outputs into a system that displays the most current information in a uniform, consolidated format. 


\section{Remote Sensing Technology}

Data Collection: To support a Bird Strike Advisory infrastructure, relevant real-time data are needed. Relevant and useful data can show where and when birds are active in the airspace used by aviation. AHAS currently uses the National Network of 144 NEXRAD Weather Radars distributed across the United States. Supplementing these radars with other national radar assets such as the radars managed by the FAA and DOD would provide:

- Redundancy in the event of a failure of a NEXRAD radar,

- Overlapping coverage at different wavelengths which will allow bird size to be estimated, an important parameter to determine strike risk,

- Greater coverage in the lower portions of the atmosphere,

- Reduction in the masking effects of terrain,

- More rapid data updates than NEXRAD.

Existing Radar Infrastructure: The types of radar that can supplement the existing NEXRAD coverage used in AHAS are the 45 Terminal Doppler Weather Radars (TDWR), 119 existing ASR-9 Radars, 110 ASR-11 Airport Surveillance Radars currently being fielded, and 39 ARSR-4 Airport Route Surveillance radars. These radars are operated by the FAA and do not include a smaller number of ASR-9 Radars and 10 ASR11 (currently being fielded) radars operated by the DOD that can also contribute to the network. Declassified data from the DOD National Defense Radars must also be incorporated into the system.

These radars represent existing national infrastructure whose inclusion in a North American Bird Strike Advisory System is limited by the lack of networking to transmit the data they collect for processing into bird activity data. AHAS has algorithms to process the data from NEXRAD radars that can be modified for use on TDWR. MIT Lincoln Labs has developed algorithms to extract bird target data from the weather channel data of the ASR-9 radar. This approach could be refined and adopted for use on many of the ASR-11 and ARSR-4 radars. The quantity and quality of data available to assess the risk of bird strikes could be significantly improved by the addition of existing radars into a North American Bird Strike Advisory System by simply networking the radars and processing the existing data. This is a goal that can be achieved in the near term of this project.

This existing radar infrastructure can provide data to manage bird strike risk in military low level airspace and weapons ranges, provide a strategic overview of bird activity in near real time, provide a source of data for refining the United States BAM, and provide a cue for an On-Airport Bird Detection Radar system.

Weather radars in Canada linked to those in the United States would allow the network to become a broad-scale system. Ultimately, Mexico can be added to the system to provide full coverage of the North American continent. Birds migrating throughout North America could be detected and monitored hours before they crossed borders providing a longer lead-time for bird activity warnings. 
Dedicated Airport Bird Detection Radars: Transport Canada has created a road map for developing an On-Airport Bird Detection Radar system. Existing approach radars frequently cannot detect birds at ranges less than 6 nautical miles due to signal processing limitations. Airports with populations of large birds hazardous to aviation such as geese, cormorants, and pelicans are locations where aircraft are most vulnerable. This roadmap outlines how recent research with bird detection radars can be leveraged to develop 3Dimensional Airport Bird Detection Radar (3D-ABDR) in the next three years. The system would be developed with sufficient resolution to provide real time warnings of impending collisions to aircrew and air traffic controllers, provide information to bird harassment teams to improve their effectiveness by day and more importantly at night when birds at airports cannot be detected visually. Once deployed, these sensors could feed back into a National or North American Bird Strike Advisory System.

Longer-term Remote Sensing Goals: Other remote sensing techniques can play an active role in bird avoidance or be used to ground truth other sensors. Thermal infrared surveillance systems are currently used in AHAS for ground truthing radar data and may have potential for monitoring birds in real time at night. Video monitoring can be used in the place of thermal imagery during daylight hours. A pilot study is being conducted to fuse 3-dimensional acoustic data of birds calling in flight with mobile Bird Radar data. If this pilot study is successful, it will mean a source of accurate data ground truthed to a specific species which can be used in validation of existing data sources and refinement of detection algorithms.

Smart dust, or a network of micro sensors, is an emerging technology that may be able to detect birds acoustically, through vibration or other passive sensors at short range. The network capability of these sensors means that large areas can be covered inexpensively. This represents the kind of emerging technologies this program should monitor for application.

The University of Oklahoma is researching the use of cellular telephone transmission as a passive radar network capable of detecting weather, birds, and aircraft in the lowest reaches of the atmosphere. This research represents one of the most powerful technologies that could allow the ubiquitous monitoring of bird activity. In ten years time it may have greater resolution and coverage than all the national radar assets combined and be the future data source for AHAS and the BAM.

Airborne radars to automate avoiding birds and microwave sources have been suggested as approaches to be used in the past but have some serious limitations associated with them. These limitations should be documented to show that this program has fully investigated all the options and if an enabling technology emerges in the future that removes these limitations; the program can "re-adopt" the concept into ongoing research.

Data Infrastructure: The underlying technology that enables AHAS and the BAM is information technology. The key areas of technology are computers and networking. Workstation computers with sufficient power to process the vast resources of data available in real or near real time are required. Also key is a high bandwidth network that 
can bring in the raw data streams for processing and provide bird warnings to the end users, pilots, and aircrew. Bringing new data sources such as FAA and DOD radars will require significant increases in network bandwidth to access the data. The doubling of computer power in computer workstations every 18 months means that as computers are replaced from the normal wear and tear of constant use 24 hours a day seven days a week, more processing can be done with the same number of computers. In the past five years, AHAS has gone from updating current conditions once an hour to once every ten minutes. The level of sophistication of the processing algorithms, the number of calculations they execute, and the quality of the data they produce have all improved consistently over the same time, enabled by the ever improving computer processing power. In just three years, computer workstations will reach $10 \mathrm{GHz}$ providing sufficient power to handle data from all the 400 national radar assets currently available in the same way AHAS currently processes data from 144 NEXRAD radars.

Data Transmission: AHAS and BAM data are currently available to pilots via the Internet. Emerging technologies such as wireless infrastructure, data broadcasting to aircraft cockpits, and other data links all require investigation to make bird hazard data readily available for bird hazard avoidance.

Data-Links: Many existing systems could be adapted to communicate bird collision hazards to the cockpit.

- TCAS Display (Traffic Collision Avoidance System) presently displays aircraft collision hazards via transponder with recommended avoidance actions and could be adapted to display bird advisory warnings in addition to present functions.

- ADS-B (Automatic Dependant Surveillance - Broadcast) is a system which allows pilots in the cockpit and air traffic controllers to "see" aircraft traffic. Using GPS, an equipped aircraft broadcasts its precise position in space via a digital data link along with other data, including airspeed and altitude, and whether the aircraft is turning, climbing, or descending.

- ACARS (Aircraft Communication Addressing and Reporting System) is a digital data link system transmitted via VHF radio and can be likened to "email for airplanes," relaying such routine items as departure reports, arrival reports, passenger loads, fuel data, and engine performance data. Messages appear to the flight crew as text on a display unit and printer. 
- Link-16 is a high-capacity, jam-resistant, secure, extended line-of-sight, flexible communication, navigation, and identification (CNI) system. It is the newest generation of tactical data links, with current and future applications to air superiority, Single Integrated Air Picture (SIAP), and air defense, surface and land warfare, and ballistic missile defense.

- Electronic Flight Bag (EFB) consists of electronic computing and/or communications equipment or systems used to display a variety of aviation data or perform a variety of aviation functions. (FAA Advisory Circular No: 120EFB). Also known as PACMAN (Pilot/Aircrew Cockpit Management and Navigation) or E-Kneeboard for portable EFBs. 


\section{APPENDIX II - Regulations}

Wildlife Planning and Management under the Canadian Aviation

Regulations (CARS):

The regulation is:

PART III-AERODROMES AND AIRPORTS-302

SUBPART 2-AIRPORTS

DIVISION XXI-AIRPORT WILDLIFE PLANNING AND MANAGEMENT

The Standard is:

STANDARDS RESPECTING DIVISION XXI-322

AIRPORT WILDLIFE PLANNING AND MANAGEMENT

The Advisory Material is:

ADVISORY DOCUMENTS-342

DIVISION XXI-AIRPORT WILDLIFE PLANNING AND MANAGEMENT

\section{US Federal Aviation Administration Guidance:}

AC 150/5200-33: FAA ADVISORY CIRCULAR: HAZARDOUS WILDLIFE ATTRACTANTS ON OR NEAR AIRPORTS

Title 14 Code of Federal Regulations Part 139, Sec. 139.337: CERTIFICATION AND

OPERATIONS: LAND AIRPORTS SERVING CERTAIN AIR CARRIERS

CertAlert 97-02: RELATIONSHIP BETWEEN FAA AND USDA/WILDLIFE SERVICES

CertAlert 97-05: GRASS ATTRACTIVE TO HAZARDOUS WILDLIFE

CertAlert 97-09: WILDLIFE HAZARD MANAGEMENT PLAN OUTLINE 


\section{US Air Force Guidance:}

AFI 91-202, Chapter 7.11 (1 August 1998): THE US AIR FORCE MISHAP PREVENTION PROGRAM

AFI 91-204, Chapter 7.4.7 (11 December 2001): SAFETY INVESTIGATIONS AND REPORTS

AFPAM 91-212 (1 April 1997): BIRD AIRCRAFT STRIKE HAZARD (BASH) MANAGEMENT TECHNIQUES

AFI 32-7064 (1 August 1997): INTEGRATED NATURAL RESOURCES MANAGEMENT

AFI 13-213 (9 September 2002): AIRFIELD MANAGEMENT

\section{US Navy Guidance:}

OPNAVINST 5909.1B CH-3 (17 October 2002): Environmental and Natural Resources Program Manual

NAVFAC P-73 Procedural Manual, Volume II, (May 1987): Currently under review for updating.

OPNAVINST 3750.6R Chg 1: Naval Aviation Safety Program 


\section{APPENDIX III - Supporting Documentation}

Herricks, E. E. et al. 2004. Development of a National Wildlife Hazard Advisory System (WHAS): Phase 1 - Risk Issues at Airports. FAA Technical Report.

Kelly, T. A. 2004. A Roadmap for the Development of a 3-D Bird Detection Radar System for use at Commercial Airports in Canada. Transport Canada Technical Paper.

Ruhe, W. 2004. United States Alaska Bird Avoidance Model (Alaska-BAM) Technical Development Manual. USAF Safety Center Technical Manual.

Larkin, R. P. 2004. Review \& Assessment of Radar/Sensor Application in WHAS. FAA Technical Review Report.

Herricks, E. E. et al. 2004. A System Level Review of U.S. Air Force Bird Aircraft Strike Hazard Products - Bird Avoidance Model and Avian Hazard Advisory System. FAA Technical Report.

Herricks, E. E. et al. 2005. A Report of Technical Results of the $94 \mathrm{GHz}$ Bird Detection Radar (BIRDAR) at DFW Airport. FAA Technical Report.

North Atlantic Treaty Organization STANAG 3879 (Edition 5): Standardization Agreement on Birdstrike Risk/Warning Procedures (EUROPE) 